\title{
O efeito de número sôbre o consumo de oxigênio por Crustáceos Decápodos
}

\author{
por \\ Domingos Valente \\ Lic. em Ciências Naturais
}

\section{Introdução}

No presente trabalho pretendo relatar os resultados de algumas experiências sôbre o consumo de oxigênio por crustáceos dágua doce da sub-família Trichodactylina em função da "massa fisiológica" Esta designação é usada, na fisiologia comparativa, para indicar o efeito de número ou de grupo determinando modificações de certas atividades dos animais.

Nêstes estudos são dignos de nota os trabalhos de Schlaifer, realizados em peixes (Carassius a uratus). Verificou êsse autor (1938, p. 4ll) que, em um dado volume dágua, um peixe consóme isoladamente mais oxigênio e possui maior atividade locomotôra do que cada um dos peixes de um grupo de dois e também de um grupo de quatro. Posteriormente (1939, p. 382), - mesmo autor efetuou uma série de experiências interessantes com peixes daquéla espécie, sôbre o efeito de grupo relacionado a diferenças de ambiente. De tais estudos concluiu que o efeito de número sôbre o consumo dé oxigênio pelos citados peixēs, grupados ou isolados, se manifesta por uma diminuição do gasto de oxigênio quando em grupo. Além disso, os animais colocados no escuro ou cegados não apresentam tal diminuição. $O$ gasto de oxigênio por peixes isolados é diminuido quando êles se acham dispostos de tal modo que possam vêr a própria imagem refletida em um espelho. Este fáto é para Schlaifer um índice dé que a visão exerce influência sôbre a massa fisiológica.

Na base de tais experiências, procurei estudar, por sugestão do Prof. Dr. Paulo Sawaya, o comportamento de certos Crustáceos-Decápodos, Tri chodactylus petropolitanus Göldi, habitantes mais frequentes do Ria Tietê e de' seus afluentes, nos arredores de São Paulc, e outros da mesma espécie das circunvizinhanças de Curitiba.

Nesta nota preliminar tive 0 intúito de verificar se tambem nêstes animais se observaria o chamado "efeito de grupo" ou "de número" e a da "imágem especular", tal como nos peixes pesquizados por Schlaifer. 


\section{Material e técnica}

O consumo de oxigênio foi determinado pelo método de Winkler, segundo a técnica mencionada por Werescagin, Anickova e Forsch (1928, p. 10) (*). Antes de iniciadas as experiências, os crustáceos permaneceram algum tempo em tanques com água de torneira, afim de se adaptarem às novas condições do ambiente. Daí eram, depois de pesados (todos os crustáceos usados pesavam de 19 a 20 grs. e mediam de $30-40 \mathrm{~mm}$. de comprimento), removidos para aquários com a capacidade de $3.500 \mathrm{cc}$. contendo água de torneira cujo teôr de oxigênio havia sido previamente determinado. Imersos os animais nágua, fechava-se a superfície líquida com uma camada de óleo de vaselina de $3 \mathrm{~cm}$ de espessura. Os animais permaneciam no aquário durante duas horas e meia, sendo as dosagens realizadas em intervalos de 30 minutos. A temperatura da água do aquário foi anotada dunante todo o tempo, tendo-se verificado uma oscilação entre 21 e $24^{\circ} \mathrm{C}$. Para o efeito de imágens especulares, colocou-se, numa das paredes verticais do aquário, um espelho plano.

\section{Parte experimental}

Foram efetuadas as seguintes experiências:

1) Efeito de grupo e efeito de escuro: Em um aquário com paredes transparêntes, mediu-se, à luz do dia, o consumo de oxigênio por animais agrupados e isolados. Para o escuro foi usado o mesmo aquário hermeticamente encerrado numa camara de papél preto impermeavel à luz do dia. Os resultados das análises do oxigênio gasto foram os seguintes:

TABELA I

\begin{tabular}{|c|c|c|c|c|c|c|}
\hline \multirow{4}{*}{$\frac{\text { Período }}{\text { Minutos }}$} & \multicolumn{3}{|c|}{ Um Trichodactylus isolado } & \multicolumn{3}{|c|}{ Grupo de 4 Trichodactylus } \\
\hline & \multirow{3}{*}{$\begin{array}{c}\text { Número de } \\
\text { casos }\end{array}$} & \multirow{2}{*}{\multicolumn{2}{|c|}{$\begin{array}{l}\text { Média de } \mathrm{O}_{2} \text { em cc. } \\
\text { consumida por an:mal }\end{array}$}} & \multirow{3}{*}{$\int_{\text {casos }}^{\text {Número de }}$} & \multirow{2}{*}{\multicolumn{2}{|c|}{$\begin{array}{l}\text { Média de } O_{2} \text { em cc. } \\
\text { consumida por animal }\end{array}$}} \\
\hline & & & & & & \\
\hline & & Luz do dia & Escuro & & Luz do dia & Escuro \\
\hline $\begin{array}{r}30 \\
60 \\
90 \\
120 \\
\end{array}$ & $\begin{array}{l}8 \times 1 \\
8 \times 1 \\
8 \times 1 \\
8 \times 1\end{array}$ & $\begin{array}{l}0,197 \\
0,199 \\
0,196 \\
0,176\end{array}$ & $\begin{array}{l}0,252 \\
0,081 \\
0,329 \\
0,011\end{array}$ & $\begin{array}{l}4 \times 4 \\
4 \times 4 \\
4 \times 4 \\
4 \times 4 \\
\end{array}$ & $\begin{array}{l}0,119 \\
0,113 \\
0,089 \\
0,059\end{array}$ & $\begin{array}{l}0,115 \\
0,089 \\
0,077 \\
0,084\end{array}$ \\
\hline $\begin{array}{l}\text { Consumo } \\
\text { por hora }\end{array}$ & $\begin{array}{l}\text { de oxigênio } \\
\text { por animal }\end{array}$ & 0,384 & 0,3365 & & 0,190 & 0,1825 \\
\hline
\end{tabular}

$\left.1^{*}\right)$ Agradeço ao licenciado Erasmo G. Mendes, 1.0 assistente de Fisiologia Geral e Animal o auxílio prestado nas várias determinaçōes. 
Na tabéla 1 os números relativos ao consumo de oxigênio, em cada meia hora, correspondem à média de oito determinações, não figurando aí a primeira determinação de oxigênio do aquário, antes de néla ser imerso o crustráceo.

Pela análise desta tabéla verifica-se que, em ambiente claro, o crustáceo isolado consome em média $0,384 \mathrm{cc}$. de oxigênio por hora. 0 mesmo animal, em grupo de quatro, no mesmo ambiente, passa a consumir 0,190 cc. de oxigênio em igual tempo. Há, como se vê, uma decisiva influência da agregação sôbre a respiração; no grupo, o crustáceo passa a consumir metade do oxigênio que usa quando isoliado.

Tal como fez Schlaifer (1938, p. 412) com Carassius a u ratus procurei também observar se a luz exerceria influência sôbre êste efeito de grupo, uma vez que, na ausência dêste fator, o efeito é abolido. O mesmo, porém, não acontece com o crustáceo aquí estudado. Na referida tabéla vê-se que o crustáceo isolado consome, ém média, 0,3365 cc. de oxigênio por hora, no escuro, e, quando agrupado com outros três, passa a consumir, no mesmo tempo, $0,1825 \mathrm{cc}$. de oxigênio, ou seja aproximadamente a metaje.

2) Efeito de imágens especularés: Tendo verificado ser positivo o efeito de grupo em Trichodactylus e a não influência da luz sôbre o mesmo, passei a estudar o efeito de imágens especulares. Procurei principalmente indagar se cada Trichodactylus formando artificialmente um grupo de quatro (dois animais em frente de uma parede espelhada do aquáriol consumiria menos oxigênio que cada um no grupo natural de quatro. Schlaifer (1939, p. 386) estudou o efeito de imágens especulares empregando um Carassius em um aquário com duas parede's espelhadas formando ângulo. Circunstâncias especiais impediram-me de seguir esta tecnica com os crustáceos, o que espero poder efetuar futuramente.

Os resultados das determinações das quantidades de $\mathrm{O}_{2}$ gastos acham-se expressos na tabéla II.

TABÉLA II

\begin{tabular}{|c|c|c|c|c|c|}
\hline \multirow[b]{2}{*}{ Horas } & \multicolumn{2}{|c|}{$x$ Testemunhas } & \multicolumn{2}{|c|}{ xx Experimentados } & \multirow{2}{*}{$\begin{array}{l}\text { Diferença } \\
\text { - média }\end{array}$} \\
\hline & $\begin{array}{c}\text { Número de } \\
\text { casos }\end{array}$ & $\begin{array}{c}\text { Média de } 0_{a} \text { em cc. } \\
\text { consumida pelos } \\
\text { animais }\end{array}$ & $\begin{array}{c}\text { Número de } \\
\text { casos }\end{array}$ & $\begin{array}{c}\text { Média de } O_{\text {a }} \text { em cc. } \\
\text { consumida pelos } \\
\text { animais }\end{array}$ & \\
\hline 2 & $4 \times 2$ & 1,504 & $4 \times 2$ & 0,961 & 0,543 \\
\hline
\end{tabular}

$x$ Dois animais em aquário não espelhado.

xx Dois animais num aquário com uma parede espelhada.

Foram feitas oito determinações, colocando-se, primeiramente, dois animais no aquário sem espelho. Conforme se vê na tabéla II, êstes crustáceos consumiram 0,752 cc. de oxigênio por hora $(1,504: 2)$ ou seja cada um 0,376 cc.. A seguir, foram os animais transportados para um aquário com 
uma parede espethada. $O$ consumo de oxigênio por hora por ambos os crustáceos foi de 0,4805 cc. $(0,961: 2)$ o que corresponde a 0,2402 cc. de oxigênio por animal numa hora. É digna de nota a consideravel diminuição dé consumo de oxigênio pelos animais em presença de sua própria imágem nefletida em um espelho plano.

\section{Discussão}

Embóra se trate de animais bem diversos dáqueles usados por Schlaifer, mas vivendo todos na água doce, pode-se dizer que os Trichodactylus, como os $\mathrm{C}$ arassius mostram, com evidência, o chamado efeito de grupo ou de número. Como êsses peixes, os crustáceos por mim usados apresentanam sensivel redução de consumo do oxigênio por hora, quando colocados no aquário em grupo de 4, com a diferença, porém, de que, nos crustáceos, - fenômeno é mais acentuado, como se pode deduzir da comparação dos meus resultados com os daquele autor (1938, p. 412). Além disso, enquanto que, nos $\mathrm{C}$ arassius foi demonstrado desaparecer o efeito de grupo no escuro, nos Trichodactylus tal não se dá, i. é, na ausência da luz os animais em grupo de 4 continuam a consumir, cada um, menos oxigênio que isoladamente. Este fato, aliás, está de acondo com o modo de vida dêsses Decápodos. Como se sabe, Trichodactylus habitam os rios e riachos, colocando-se debaixo das pedras, nas lócas, sob a vegetação, isto é, em ambiente por assim dizer escuro. Eu próprio pude muitas vezes verificar o seu fototatismo negativo, colocando uma caixa com abertura lateral emborcada no tanque em que os animais eram mantidos; imediatamente todos os Trichodactylus intrometiam-se na caixa pela abertura referida, em busca da obscuridade. Tal diferença de comportamento dos Tirichodactylus em relação aos Carassius poderá ser também levada à conta da pouca mobilidade que os caracteriza, em oposição à atividade peculiar daquelés peixes. O próprio Schlaifer (1939, p. 423) concluiu de suas experiências que, em um dado volume de água, um peixe isolado não só consome mais oxigênio como tem maior atividade locomotôra do que cada peixe em grupo de 2 e de 4 . Em todas as minhas experiências, os crustáceos se caracterizavam por uma peculiar imobilidade no fundo do aquário.

Quanto à influência de imágem especular, de acôrdo com os meus resultados, vê-se que a quantidade de oxigênio consumida diminui quando os crustácéos são colocados em frente de um espelho plano, fal como se dá com os Carassius Todavia, esta diminuição do consumo de oxigênio por efeito da imagem especular não atinge àquela verificarda quando os animais estão num grupo natural de 4, como se póde deduzir pela comparação dos resultados dé ambas as tabélas. Reralmente, no grupo artificial cada Trichodactylus gastou $0,2402 \mathrm{cc}$. de oxigênio por hora enquanto que foi dé 0,190 cc. o gasto em igual tempo, por animal, no grupo natural. Deve-se levar em conta que, no grupo artificial, tendo utilisado dois crustáceos, deve ter havido uma certa influência do efeito de grupo. Isto quer dizer que, aquí no caso, a diminuição do consumo de oxigênio corre cor conta, não somente do feito de imágem especular como também do eféito 
de grupo. Parece, pois que a influência da imágem especular não é tão sensivel na atividade respiratória destes crustáceos.

Na literatura consultada à disposição, não logrei encontrar referência alguma sôbre o chamado efeito de grupo em Crustáceos-Decápodos. Sendo Trichodactylus petropolitanus Göldi um Decápodo exc'usivamente sul-americano, quero crêr não tenha sido ainda objéto de pesquisas deste gênero.

Com referência a esta classe de Artropodos apenas me foi dado ler o trab'alho de Allee (1926, p. 255) relativo às causas e aos éfeitos de ajuntan:ento de Isópodos terrestres, e outro (1927), sobre as agregações animais onde menciona Aseltus (p. 37I) e' Daphnia (p. 383) entre os crustáceos.

Finalmente, na interpretação do efeito de grupo, Schlaifer (1939, p. 392) acenirúa ser a visão o sentido mais envolvido no fenômeno nos peixes, o que foi também demonstrado por Bowen (1931, p. 269) em Am e iurus melas. Tais asserções baseiam-se no fato de ser anulado o efeito de grupo nos animais mantidos na obscuridade ou cegados. Nos meus crustáceos, não se dando a anulação do mencionado efeito no escuro, quero crer que outras sejam as causas que possam explicar este singular comportamento dos Trichodactylus. A elucidação deste ponto requer, pois, novas investigações.

Os resultados das experiências acima mencionadas podem ser resumidos nas seguintes conclusões:

1) $\mathrm{O}$ efeito de número sôbre o consumo de $\mathrm{O}_{2}$ em Trichod actylus petropolitanus Göldi, agrupados e isolados manifesta-se por uma sensivel diminuição de consumo de $\mathrm{O}_{2}$ por animat no grupo.

2) A obscuridade não anula este efeito.

3) $\mathrm{O}_{2}$ consumido por Trichodactylus isoladamente, é diminuido quando os animais são colocados em contáto com sua imágem refletida por um espelho plano.

\section{Summary}

Some experiments dealing with the so called "group effect" in animals were performed on Trichodactylus petropolitanus Göldi (Crustacea-Decapoda-Brachyura). These crabs are very frequent in South American freshwaters. All experiments were performed within doors in the Laboratory of General and Animal Physiology of the Department of Zoology. Some days before the determination of the oxygen consumption, the animals were placed in tap water. All the crustaceans were adults, mesuring $30-40 \mathrm{~mm}$ in length and weighing 20 grs. The technique used throughout was the Winkler method as indicated by Werescagin, Anickova, \& Forsch (1939, p. 65). For the effect of darkness the $3.500 \mathrm{cc}$. aquarium was placed in a dark box impermeable to light. Control tests were made with crabs placed in groups of two in ordinary daylight, free from sunlight. Attempts were made to investigate the role of visual stimuli in aggregations of these crabs. The aquarium used for control tests had four transparent vertical glass sides; those used for the experimental conditions were mirrored on one vertical side. 
The data in Table I show a significative fall in oxygen consumption of the single crab in a group of four, that is, isolated crabs consume more oxygen than do those in a group of four. Reference of the same Table I indicates that, in daylight, the oxygen consumption of two crabs is significantly higher than that of crabs in groups of four, and this "group effect" is not affected by darkness. These results do not agree with those obtained by Schlaifer (1939, p. 383) with Goldfish. Trichodactylus petropolitanus lives in darkness in the rivers, generally under stones and water plants:

The data in Table II show an expressive fall in oxygen consumption of the isolated crab in the mirrored aquarium. The effect of mirror images is positive on Trichodactylus. I used in these experiments two crabs for control tests and, later, these animals were transported to the mirrored aquarium. Consequently, there is superposition of two effects: of "group" and of "mirror images" The oxygen consumption by each crab in control test $(0,376$ cc. per hour) was higher than that used by each crab in mirrored aquarium $(0,2402$ cc. per hour). It seems that the "mirror images effect:". is not very intensive on Trichodactylus.

Conclusions:

1) The effect of numbers upon the oxygen consumption of grouped and isolated freshwater crabs Trichodactylus petropolitanus Göldi, manifested itself by an increased rate of oxygen use in the isolated animal,

2) Darkness does not eliminate this effect.

3) The oxygen consumption of isolated crabs decreases when they are placed in contact with their own mirror images.

\section{Bibliografia}

ALLEE, W. C. 1926. Studies in Animal Aggregations: Causes and Effects of Bunching in Land Isopods. Journ. Exper. Zool., v. 45, pp. 255-277. Philadelphia, Pa.

- 1927. Animal a.ggregations, Quart. Rev. Biol., v. 2, pp. 367-398, Balt more.

BOWEN, E. S. 1932. Further studies of the Aggregating Behavior of Ameiurus melas. Biol. Bull., v. 63, n. 2, pp. 258-270, Lancaster, Pa.

SCHLAIFER, A. 1938. Studies in Mass Physiology: Effect of Numbers upon the Oxygen Consumption and Locomotor Activity of Carassius auratus. Physiol. Zoöl., v. II, n. 4 pp. 408-424, Chicago.

-- 1939. On Analysis of the Effect of Numbers upon the Oxygen consumption "of Carassius auratus. Ibidem, v. 12, n. 4, pp. 381-392.

WERESCAGIN, G. J., ANICKOVA, N. J. V. FORSCH, T. B. 1931. Methoden der hydrochemischen Analyse in der limnologischen Praxis. 230 pp. Stuttgart. 